\title{
EVALUATION OF RENAL RESISTANCES, WITH SPECIAL REFERENCE TO CHANGES IN ESSENTIAL HYPERTENSION ${ }^{1}$
}

\author{
BY DOMINGO M. GÓMEZ \\ (From the Department of Physiology, New York University \\ College of Medicine, New York, N.Y.)
}

(Submitted for publication December 13, 1950; accepted August 6, 1951)

We have elsewhere (1) treated the theoretic aspects of renal hemodynamics at some length, and there presented methods for the evaluation of the physical characteristics of the renal vascular tree. Unfortunately the application of these methods requires precise knowledge of certain variables not available at the present time. It is, however, possible by means of warrantable, simplifying assumptions to effect such simplification in the analytic approach as to make possible the calculation of the major renal resistances from clinically available data. This paper comprises a statement of the necessary assumptions, the equations based thereon, and the calculation of renal resistances in the normal human kidney and in subjects with hypertensive disease.

For practical computation the renal vascular tree can be divided into five functional segments :
$A=$ Afferent vessels
$\mathrm{B}=$ Glomerular capillaries
$\mathrm{C}=$ Efferent arterioles
$\mathrm{D}=$ Peritubular capillaries
$\mathrm{E}=$ Venules and veins

If the conditions in the intermediate segments $B$ and $D$ can be specified, the characteristics of the other three vascular segments $\mathrm{A}, \mathrm{C}$ and $\mathrm{E}$, can be approximately evaluated.

Glomerular and peritubular capillaries. Collating the available data on the nature of the fluid flow in capillaries (2), the relative viscosity of the blood for specified plasma protein concentration (3), and hematocrit $(4,5)$, the dimensions and number of the glomerular capillaries (6), and the blood flow through the glomerular capillary bed (7), it may be deduced that the glomerular capillaries contribute some 1.8 to 9 per cent of the total renal resistance; i.e., the drop in pressure along the glomerular capillaries is of the order of 1.4 to $7 \mathrm{~mm}$. $\mathrm{Hg}$, a value negligibly small as compared to the drop in pressure across the kidney as a whole (some $80 \mathrm{~mm}$. $\mathrm{Hg}$ in normal subjects). This conclusion is supported by the fact that in different species the drop of pressure between the arteriolar and venous end

\footnotetext{
1 Aided by grants from the Knapp Foundation and the Commonwealth Fund.
}

of the capillaries of the systemic circulation ranges from 3 to $20 \mathrm{~mm}$. $\mathrm{Hg}(8)$.

As compared with the glomerular capillaries, the peritubular capillaries probably afford an equal or larger crosssectional area through which the blood moves at a relatively low velocity, and with even a smaller decrement in pressure than in the glomeruli. In the absence of precise information, it may be assumed that the contribution of both the glomerular and peritubular capillary plexus to the total renal resistance is so small that it can be neglected in practical computations.

The elementary mathematical treatment which follows, however, is such that part of the actual resistance of the glomerular capillaries is subsumed in the calculated value of $R_{\mathbf{A}}$ and part in $R_{E}$, while part of the actual resistance of the peritubular capillaries is subsumed in $R_{\mathbf{E}}$ and part in $R_{v}$. The net effect, therefore, is to introduce a slight, unavoidable but probably negligible error in each of these terms.

For the calculation of the resistances represented by $\mathrm{A}, \mathrm{C}$ and $\mathrm{E}$, it is required that we know the flow across and decrement in pressure along each segment. The four pairs of values the members of which are to be compared are:
(1) $\quad \mathrm{R}=\frac{\mathrm{P}_{\mathrm{m}}-\mathrm{P}_{\mathrm{V}}}{\mathrm{Q}} \times 1328=\mathrm{R}_{\mathrm{A}}+\mathrm{R}_{\mathrm{E}}^{\prime}+\mathrm{R}_{\mathrm{V}}$
(2) $R_{A}=\frac{P_{m}-P_{g}}{Q} \times 1328$
(3) $\quad R_{E}=\frac{P_{g}-P_{t}}{Q-q} \times 1328$
(4) $R_{v}=\frac{P_{t}-P_{v}}{Q} \times 1328$
$Q \quad=$ afferent renal blood flow
$\mathrm{q}=$ filtration rate both in cc./sec. and corrected to 1.73

sq. m. body surface area.

$P_{m}=$ mean aortic pressure

$P_{B}=$ mean glomerular pressure

$P_{t}=$ mean peritubular capillary pressure

$P_{\checkmark}=$ renal venous pressure

all pressures in $\mathrm{mm} . \mathrm{Hg}$

$\mathrm{R}=$ total renal resistance

$\mathbf{R}_{\mathbf{A}}=$ afferent resistance

$R_{\mathbf{E}}=$ true efferent resistance 


$$
\begin{gathered}
R_{E}^{\prime}=\begin{array}{c}
\text { net efferent resistance (to be defined } \\
\text { later) }
\end{array} \\
R_{\nabla}=\begin{array}{c}
\text { venular resistance } \\
\text { all resistances in dynes. } \mathrm{sec} . \mathrm{cm} .^{-b}
\end{array}
\end{gathered}
$$

Correction of $\mathbf{Q}$ and $q$ to standard body surface area must be made before incorporation into the equations because $(a)$ the calculated resistances will thus be automatically corrected for body size as they should be; $(b)$ the gross glomerular permeability coefficient $\bar{\lambda}$, as it appears in equation 5 , is based upon a filtration rate already corrected for body surface area.

The factor 1328 is obtained by multiplying the weight of $0.1 \mathrm{cc} . \mathrm{Hg}$ at $20^{\circ} \mathrm{C}$. (sp. gr. 13.546) by the acceleration of gravity $\left(980.6 \mathrm{~cm} . \mathrm{sec}^{-2}\right)$, transforming the pressure into absolute units or baryes (dynes. $\mathrm{cm}^{-2}$ ) which; when divided by How (cm..$^{3 / \mathrm{sec}}$.), gives dynes. sec. $\mathrm{cm} .^{-5}$.

\section{Basic premises}

I. In speaking of "resistances" as calculated above, it must be recognized, first, that the relation between fluid flow and decrement in pressure in any vascular segment is not a linear one (2, 9-11), and second, that blood viscosity $(2,4,12)$ and the force (the parameter, $\pi$ ) of permanent contraction of the smooth muscular fibers of the vascular wall ${ }^{2}(2,13-17)$ complicate the simple concept of "resistance" as a ratio of the decrement in pressure along a vascular segment to the flow. That is, this ratio does not constitute a resistance in the strict sense of Poiseuille's law or Ohm's law; neither does it constitute a conductance in the sense in which this word has

2 The parameter, $\pi$, which has the dimensions of a pressure, has been identified by the writer with the active force of permanent semi-contraction of the smooth muscular fibers of the vascular walls. Together with the internal viscous resistivity of the arterial walls, the parameter $\pi$ plays a most important role in the dynamic cubic expansion of the arterial reservoir (2). It also constitutes the preponderant factor determining the changes in frictional resistance to blood flow in the small vessels, the caliber of which is essentially defined by the value of this parameter (13-17). With this last connotation the existence of the parameter $\pi$ has been subsequently recognized by Aperia (18) who, with the designation of "virtual static pressure" which we originally used, has made wide use of it in his hemodynamic studies. The significance of this parameter has been recently stressed again (19). A first attempt has been made to introduce this parameter in renal hemodynamics (1), but further experimental information is needed before such a concept can be used in clinical research (20). been used by the writer $(2,13-16)$. But in identifying the above ratios as "resistances," we are following widely accepted hemodynamic usage. The chief consequence of this approximation is that "resistance" as here calculated will not vary strictly as the inverse of the fourth power of vessel diameter, as in the simple statement of Poiseuille's law, though changes in the resistance thus calculated will always represent changes in vascular diameter.

II. The following treatment neglects the loss of fluid from the blood as urine, which is not significant except at very large urine flows, and loss of fluid as lymph, the magnitude of which is small but unknown.

III. It is assumed that glomerular plasma flow and peritubular plasma flow represent an identical stream from which glomerular clearance is effected first, followed by tubular clearance and tubular reabsorption.

IV. It is assumed that the glomerular filtrate and the renal interstitial fluid are protein-free.

V. It is assumed that the specific permeability coefficient of the glomerular capillaries is constant in all subjects without glomerular disease, and excluding the limiting conditions discussed below.

VI. It is assumed that glomerular surface area is proportional to body surface area.

\section{Calculation of total renal resistance, $R$}

$P_{m}, P_{v}$ and $Q$ are clinically determinable, and therefore equation 1 may be solved directly.

$P_{m}$ may be measured directly from the brachial or femoral artery, or estimated as $P_{d}+k\left(P_{k}-\right.$ $P_{d}$ ), where $P_{s}$ and $P_{d}$ are systolic and diastolic auscultatory determinations and $k$ is a factor ${ }^{8}$

An approximate value of $\mathrm{k}$ is given by the formula

$$
k=0.77 \gamma+\rho(1-\gamma)
$$

where $\boldsymbol{\gamma}$ is the ratio of the duration of the systolic ejection phase to the entire duration of the cardiac cycle and $\rho$ is the fraction of the pulse pressure corresponding to the mean value of the amplitude during diastole. Expressed in terms of the pulse rate, $N, \gamma$ and $\rho$ have the values

and

$$
\gamma=\frac{2.3 \sqrt{N}}{60}
$$

$$
\rho=\frac{12(3 \gamma+1)}{100}
$$

When $\mathbf{N}$ is between 60 and 80 , the value of $k$ varies between about 0.390 and $\mathbf{0 . 4 5}$, in agreement with figures given in the literature. These equations are not valid in aortic insufficiency, pulsus alternans, and auricular fibrillation. 
averaging 0.44 (21), or by other indirect means (2, 22-28).

$P_{r}$ may be measured by catheterization of the renal vein, or taken as equal to femoral venous pressure. Where the peripheral venous pressure is not increased, $P_{\checkmark}$ may be taken as $10 \mathrm{~mm} . \mathrm{Hg}$ on the basis of average normal values. Where the venous pressure is greatly elevated, as in chronic congestive cardiac failure, $P_{v}$ may be taken as equal to the peripheral venous pressure $(29,30)$.

$Q$ is the effective renal blood flow as measured by the PAH or diodrast clearance without reference to the extraction ratio.

\section{Calculation of afferent arteriolar resistance, $R_{\mathrm{A}}$}

This calculation involves $\mathrm{P}_{m}$ (vide supra) and the mean glomerular pressure, $P_{k}$; the latter cannot be measured directly and must therefore be computed. The method of computation which follows is based on the accepted principle that the rate of glomerular filtration is proportional to the difference between the total mean glomerular pressure, $P_{g}$, and the sum of the mean oncotic pressure (h) and intracapsular (= interstitial) pressure $(\mathrm{H})$. In the Starling-Cushny hypothesis of glomerular filtration, the glomerular membranes may be conceived to be a uniform filter possessing a fixed permeability to water which is the same in all normal subjects and which can be designated by $\bar{\lambda}$, a gross permeability coefficient corrected for body surface area. Hence

$$
q=\bar{\lambda}\left(P_{k}-h-H\right)
$$

Equation 5 is derived as follows: if $q^{\prime}$ is the filtration rate uncorrected for surface area, and $\lambda$ the gross permeability coefficient in any individual,

$$
q^{\prime}=\lambda\left(P_{g}-h-H\right)
$$

but,

$$
\lambda=\mathrm{GS}_{\mathrm{s}}
$$

where $\epsilon$ is the specific glomerular permeability coefficient (cc./sec. per unit glomerular surface area per unit effective glomerular pressure) and $S_{z}$ is the total glomerular surface area. Where renal function is corrected to standard body surface area, we may designate these quantities by $\bar{\lambda}$ and $\bar{S}_{z}$, so that

(8)

$$
\bar{\lambda}=\overline{\mathbf{S}}_{\mathbf{g}}
$$

Dividing (7) by ( 8 ,

$$
\lambda=\frac{\mathrm{S}_{\mathrm{g}} \bar{\lambda}}{\overline{\mathrm{S}}_{\mathrm{g}}}
$$

Under premise VI, glomerular surface area is taken as proportional to body surface area, $S$, and consequently

$$
\lambda=\frac{S \bar{\lambda}}{\bar{S}}
$$

Substituting 10 in 6 ,

$$
q^{\prime}=\bar{\lambda} \frac{S}{\bar{S}}\left(P_{g}-h-H\right)
$$

Since by definition $q=q^{\prime} \frac{\bar{S}}{S}$

$$
\mathrm{q}=\bar{\lambda}\left(\mathrm{P}_{\mathrm{g}}-\mathrm{h}-\mathrm{H}\right)
$$

In obtaining the normal value of $\bar{\lambda}$, we must assign a value to the mean glomerular pressure, $P_{g}$, applicable to the statistical average normal subject. Winton's (31) indirect estimates in the dog indicate that the glomerular pressure is about two-thirds of the mean aortic pressure; taking the latter as $90 \mathrm{~mm}$. $\mathrm{Hg}$ in normal subjects under standard conditions, we assign a value to $P_{g}$ of $60 \mathrm{~mm}$. $\mathrm{Hg}{ }^{4}$ By taking $q$ as $2.167 \mathrm{cc} . / \mathrm{sec}$. (130 cc./min.) (32), and $\mathrm{h}$ and $H$ as 25 and $10 \mathrm{~mm}$. $\mathrm{Hg}$ on the basis of average normal values, $\bar{\lambda}=0.0867$.

Rearranging equation 5 ,

$$
P_{s}=h+H+\frac{q}{\bar{\lambda}}
$$

Observations on the filtration rate, pelvic and interstitial pressures in dogs indicate that so long as the urine flow does not exceed 10 per cent of the filtration rate, the pressure in Bowman's capsule must be practically identical with the interstitial pressure (20). Consequently we utilize interstitial pressure, $\mathrm{H}$, in equation 12 as a substitution for intracapsular pressure.

We have shown elsewhere (1) that the conditions determining interstitial pressure are such that, for wide variations in all renal resistances,

- The selection of this value in order to define the properties of the normal glomerular membranes is arbitrary and might be designated as an additional premise. Actually, the value of $P_{g}$ within the range 55 to $65 \mathrm{~mm}$. $\mathrm{Hg}$ assumed in calculating $\bar{\lambda}$ has only a moderate influence upon the calculated value of $R_{\mathbf{A}}, R_{E}$ and $R_{E}^{\prime}$, and no influence upon $\mathbf{R}_{\mathbf{v}}$. 
this pressure is predominantly dependent on renal venous pressure, $P_{\mathbf{v}}$.

The interstitial pressure, $H$, surrounding the renal venous network is properly defined by the relation

$$
H=\frac{2 K+a P_{v}+a K+a \sqrt{\left(P_{v}-K\right)^{2}+\pi^{2}(1+a)}}{2(a+1)}
$$

with

$$
K=\left(P_{m}-h_{o}\right)-\frac{a}{2}\left(h_{0}+\sqrt{\left.h_{o}^{2}+\pi^{2}\right)}\right.
$$

where $h_{o}$ is the minimum oncotic pressure, $K$ is a lower limiting pressure mentioned below, and a is a coefficient given by the product of the resistance from the aorta to the peritubular capillary network multiplied by the maximum conductance of the venous system (20). The symbol $\pi$, which has the dimensions of a pressure, is a parameter depending on the thickness of the vascular walls. When the latter is small, $\pi$ is also small and the interstitial pressure varies as a function of the venous pressure as indicated above.

The renal interstitial pressure is also approximately defined (1) by the formula

$$
H=\frac{R_{\mathbf{V}} P_{\mathbf{m}}+\left(R_{\mathbf{A}}+R_{E}^{\prime}\right) P_{\mathbf{V}}}{R_{\mathbf{A}}+R_{\mathbf{E}}^{\prime}+R_{\mathbf{V}}}-h_{\text {。 }}
$$

in which each symbol is defined in the text. When the venular resistance $R_{y}$ is considered as being passively influenced by the difference between the intravascular blood pressure and the extravascular pressure, $\mathrm{H}$, the statement made in the text continues to hold within certain limits.

The above equations, however, contain renal characteristics for which values are not directly ascertainable, and consequently we must at present use the approximation method of relating $\mathrm{H}$ to $\mathrm{P}_{\mathrm{v}}$.

In theory, it may be expected that interstitial pressure will have a minimal value which is independent of $P_{\nabla}$ when the latter is below a limiting value, $K$, but to increase with and approach $P_{v}$ where the latter is above this limit. This relationship has been confirmed experimentally $(33,34)$ in dogs and other mammals, the data showing that $\mathrm{H}$ has a value of about $10 \mathrm{~mm} . \mathrm{Hg}$ so long as $P_{v}$ is normal, and approaches $P_{V}$ rapidly as the latter is increased.

Hence $\mathrm{H}$ is taken as $10 \mathrm{~mm}$. $\mathrm{Hg}$ for normal renal venous pressures and as equal to the renal venous pressure when the latter is greater than $10 \mathrm{~mm}$. $\mathrm{Hg}$.

The oncotic pressure, $h$, can be calculated from the mean plasma protein concentration, $\mathrm{C}_{\mathrm{m}}$, in the glomerular capillaries, ${ }^{,}$which in turn can be calculated from $C_{A}$, the con-

\footnotetext{
- It is obvious that the effective mean oncotic pressure in the peritubular capillaries will be slightly lower than in the glomeruli. To correct for this factor, however, one has to introduce involved calculations which, in view of the approximate nature of all equations pertaining to renal
}

centration in the afferent plasma (in $\mathrm{gm} . / 100 \mathrm{cc}$.), the renal plasma flow, $Q^{\prime}$, and the filtration rate, $q$, or alternatively from the filtration fraction, $F\left(=q / Q^{\prime}\right)$ :

$$
\text { (16) } C_{m}=C_{A} \frac{Q^{\prime}}{q} \ln \frac{Q^{\prime}}{Q^{\prime}-q}=\frac{C_{A}}{F} \ln \left(\frac{1}{1-F}\right)
$$

The variation of plasma flow $y(x)$ along the abscissa $x$ in the glomerular capillaries is a complex one (1), but can be simplified to the practically linear relation

$$
y(x)=Q^{\prime}-q \frac{x}{L}
$$

in which $L$ is the length of the glomerular capillaries. If $\mathrm{C}(\mathrm{x})$ is the protein concentration at any point, and $\mathrm{C}_{0}$ the initial concentration, one necessarily has everywhere

$$
C(x) y(x)=C_{o} Q^{\prime}
$$

and, therefore,

$$
C_{m}=\frac{1}{L} \int_{0}^{L} \frac{C_{0} Q^{\prime}}{y(x)} d x=\frac{C_{0} Q^{\prime}}{L} \int_{0}^{L} \frac{d x}{Q^{\prime}-q \frac{x}{L}}
$$

By performing the quadrature indicated here, one obtains equation 16. Alternatively one may take the arithmetic mean between $C_{A}$ and $C_{E}$, the latter being the efferent protein concentration as measured by

$$
C_{E}=C_{A} \frac{Q^{\prime}}{Q^{\prime}-q}=\frac{C_{A}}{1-F}
$$

and one obtains:

$$
C_{m}=C_{A} \frac{Q^{\prime}-q / 2}{Q^{\prime}-q}=C_{A} \frac{1-F / 2}{1-F} .
$$

Equations 16 and 21 give the same result for small values of the ratio $\mathrm{q} / \mathrm{Q}^{\prime}$, as shown by expanding in a power series the logarithmic term in 16 and the denominator in 21 , neglecting all the terms of higher order than the first.

To relate $C_{m}$ to oncotic pressure, we have used the empirical relationship

$$
\mathrm{h}=\alpha\left(\mathrm{C}_{\mathrm{m}}-\beta\right)
$$

where $\alpha$ and $\beta$ are numerical constants, the first having the dimensions of a pressure. From available data (35-39), when $C_{m}$ lies between 5 and $8, \alpha$ has a value of $5 \mathrm{~mm} . \mathrm{Hg}$ and $\beta$ has a value of 2 . When $C_{m}$ lies between 8 and 11, $\alpha$ has a value of $7.75 \mathrm{~mm}$. $\mathrm{Hg}$ and $\beta$ has a value of 4. The relationship is applicable, however, only if the albumin/total protein ratio is about $\mathbf{0 . 6 0}$ \pm 0.04 . $^{6}$

hemodynamics, are scarcely worth the elaboration. Our method of estimating $h$, as well as the method of estimating $H$, introduce slight errors in $R_{v}$, but are without significant effect on $R_{A}$ and $R_{E}$.

- The oncotic pressure can be related to plasma protein concentration and albumin total protein ratio by a more elaborate and precise formulation (20), but this need not be attempted here. The approximate relations given above are derived empirically but they can be justified by 
After calculation of $\mathrm{P}_{\mathbf{g}}$ by determination of $\mathrm{h}$ and $\mathrm{H}$ in equation 12 , substitution in equation 2 yields $R_{A}$.

\section{True efferent arteriolar resistance, $R_{E}$}

It must be noted that a quantity, q, of fluid is shunted around the efferent arterioles by filtration and tubular reabsorption of water. We must therefore distinguish between the true efferent resistance, $R_{E}$, were this shunting absent, and the net efferent resistance, $\mathrm{R}_{\mathrm{E}}^{\prime}$ (vide infra), as calculated with due allowance for the shunt.

The calculation of $R_{E}$ requires knowledge of the mean glomerular pressure, $\mathrm{P}_{\mathrm{g}}$, which is obtained as described above, and $P_{t}$, the mean pressure in the peritubular capillaries, which again must be estimated indirectly. In approaching the calculation of $\mathrm{P}_{\mathrm{t}}$, it may be noted that the permeability coefficient, $\lambda^{\prime}$, of the peritubular capillary bed must be extremely large as compared to that of the glomerular capillaries, $\bar{\lambda}$. If the ratio $\lambda^{\prime} / \bar{\lambda}$ were near unity, the blood pressure at the midpoint of the peritubular capillaries would have to approximate the value of the renal venous pressure, as can be shown by writing two equations, one, 23, for filtration, $\mathrm{q}$, and one, 24 , for reabsorption, $\overline{\overline{\mathrm{q}}}$ :

$$
\begin{aligned}
& \mathrm{q}=\bar{\lambda}\left(\mathrm{P}_{\mathrm{g}}-\mathrm{H}-\mathrm{h}\right) \\
& \overline{\overline{\mathrm{q}}}=\lambda^{\prime}\left(\mathrm{H}+\mathrm{h}-\mathrm{P}_{\mathrm{t}}\right)
\end{aligned}
$$

If we assumed that $\lambda^{\prime}=\bar{\lambda}$, and writing $q=\overline{\bar{q}}$, it would follow that

$$
P_{t}=2(h+H)-P_{g}
$$

Substituting 60 for $\mathrm{P}_{\mathrm{g}}$ and 35 for $\mathrm{H}+\mathrm{h}, \mathrm{P}_{\mathrm{t}}$ would equal $10 \mathrm{~mm}$. $\mathrm{Hg}$, a value no greater than the known renal venous pressure. This condition could exist only if the resistance to flow in the renal venules and small veins were practically zero, whereas it is well demonstrated (8) that an appreciable decrement in pressure occurs distal to the venous side of the capillary network; assuming that the renal venous system does not differ from the systemic venous system, it follows that $P_{t}$ must be assigned a value greater than $P_{v}$ by $a$ difference amounting to the fall in pressure across the venular resistance $R_{V}$, which, by equation 4,

a formal expansion in Taylor's series of the theoretical expression around selected values of protein concentration and albumin/total protein ratio. is $\mathrm{R}_{\mathrm{v} Q}$. Consequently, $\lambda^{\prime} / \bar{\lambda}$ must be greater than 1.

Approaching the question from another point of view, the volume of blood contained in the kidney is relatively large (we estimate this volume to be of the order of 15 to 30 per cent of the total kidney volume) and there is therefore no reason to suppose that the total capillary surface area per unit of blood is any less than in the systemic capillaries. It has been estimated that in the horse, dog and frog, 1 cc. of systemic blood is exposed to a capillary surface area of $7,300,5,600$ and 2,700 sq. cm., respectively $(40,8)$. Translating the above figures directly, and assuming a weight of $150 \mathrm{gm}$. per kidney, the total capillary surface area of the two kidneys would be of the order of 225,000 to 450,000 sq. $\mathrm{cm}$. The surface area of the glomerular capillaries in man is variously estimated to be $15,600(6,40)$ and 7,600 sq. cm. (41). If the specific permeability coefficients (per unit surface area) were the same for both networks, the ratio $\lambda^{\prime} / \bar{\lambda}$ would be of the order of 15 or 60 to 1 . The pressure required to effect the separation of the glomerular filtrate is scarcely more than $\left(\mathrm{P}_{\mathrm{g}}-\mathrm{h}-\mathrm{H}\right)$ or $25 \mathrm{~mm}$. $\mathrm{Hg}$; to reabsorb this same quantity of fluid through a capillary plexus 15 to 60 times as large would require proportionately less pressure, or about 0.4 to $2 \mathrm{~mm}$. $\mathrm{Hg}$. Consequently $P_{t}$ may be taken as no more than $2 \mathrm{~mm}$. $\mathrm{Hg}$ below $(\mathrm{h}+\mathrm{H})$ and the difference may be less.

From equation 24, writing $\overline{\overline{\mathrm{q}}}=\mathrm{q}$ and neglecting the urine flow,

$$
\mathrm{P}_{\mathrm{t}}=\mathrm{h}+\mathrm{H}-\frac{\mathrm{q}}{\lambda^{\prime}}
$$

If, as argued above, $\lambda^{\prime}$ is many times greater than $\bar{\lambda}$, the term $q / \lambda^{\prime}$ becomes small, as compared to the actual values of $H+h$, and equation 26 approaches the equality

$$
\mathrm{P}_{\mathrm{t}} \approx \mathrm{h}+\mathrm{H}
$$

By eliminating $\mathrm{h}+\mathrm{H}$ between equations 23 and 26 , one has

$$
q=\frac{\bar{\lambda} \lambda^{\prime}}{\bar{\lambda}+\lambda^{\prime}}\left(P_{g}-P_{t}\right)
$$

where $\frac{\bar{\lambda} \lambda^{\prime}}{\bar{\lambda}+\lambda^{\prime}}$ is equal to the compound total permeability of glomerular and peritubular 
capillaries. Since $\lambda^{\prime} \gg \bar{\lambda}$,

$$
\frac{\bar{\lambda} \lambda^{\prime}}{\bar{\lambda}+\lambda^{\prime}} \approx \bar{\lambda}
$$

and 28 becomes

$$
\mathrm{q} \approx \bar{\lambda}\left(\mathrm{P}_{\mathrm{g}}-\mathrm{P}_{\mathrm{t}}\right)
$$

From 3 and 30 one obtains

$$
R_{E}=\frac{q}{\bar{\lambda}(Q-q)} \times 1328
$$

\section{Net efferent arteriolar resistance, $R^{\prime}{ }_{E}$}

In some instances it may be desirable to calculate the true efferent resistance as a distinct feature of renal function. It will be noted, however, that the glomerular filtrate which is reabsorbed by the peritubular capillaries contributes to the total renal resistance and must somehow be subsumed in equation 1 . It could appear as an independent term but it seems preferable to subsume it in the efferent resistance, and for practical purposes to calculate the net or compound parallel resistance presented by the true efferent resistance and the resistance presented by filtration and reabsorption.

This net resistance, $R_{E}^{\prime}$, is given by the total flow, $Q$, and the decrement in pressure between the glomerular and peritubular capillaries,

$$
R_{E}^{\prime}=\frac{P_{E}-P_{t}}{Q} \times 1328=R_{E} \frac{Q-q}{Q}
$$

\section{Venular resistance, $R_{V}$}

Substituting equation 27 in equation 4 ,

$$
R_{\nabla}=\frac{H+h-P_{\nabla}}{Q} \times 1328
$$

\section{Renal shunts and uncleared blood}

In the foregoing analysis we have treated the problem as though the clearance method directly gave the total renal blood flow, without reference to the extraction ratio, $E_{\text {PAB. }}$ However, only some 92 per cent of the renal arterial blood is presented to the renal parenchyma for clearance. The other 8 per cent is presumably by-passed through perirenal fat, the renal capsule, the calyces, pelvis and other non-excretory tissue (31). Conceiving this uncleared blood as comprising an integrated "uncleared shunt" around the active renal parenchyma, the flow of blood through this shunt is

$$
\frac{Q\left(1-E_{P A B}\right)}{E_{P A B}}
$$

where $E_{\mathrm{PAB}}$ (or $\mathrm{E}$ ) is the renal plasma extraction ratio of $\mathrm{PAH}$. The resistance, $\mathrm{R}_{\mathbf{s}}$, of this shunt is

$$
R_{B}=\frac{\left(P_{m}-P_{v}\right) E}{Q(1-E)} \times 1328
$$

The resistance corresponding to the effective renal blood flow is that defined in equation 1 as $R$. $R$ and $R_{B}$ are in parallel, and their combination from 1 and 35 gives the resistance, $R_{W}$, of the whole kidney (cleared and uncleared blood), which is obviously smaller than either $R$ or $R_{\mathbf{8}}$ :

$$
R_{W}=\frac{R R_{B}}{R+R_{g}}=\frac{E\left(P_{m}-P_{v}\right)}{Q} \times 1328
$$

\section{Locus of pressure equilibrium}

At some point, a, along the efferent arteriole the value of the blood pressure necessarily comes to equal the sum of the maximal oncotic pressure $h^{\prime}$ and the interstitial pressure, H. This point may be represented as a fraction, a, of the efferent arteriolar resistance encountered between the end of the glomerulus, in the sense where filtration ceases, and the beginning of the peritubular capillaries, in the sense where capillary reabsorption begins, this entire length representing the efferent arteriolar resistance, $R_{E}$. The maximal oncotic pressure, $h^{\prime}$, is given by

$$
h^{\prime}=\alpha\left(C_{E}-\beta\right)
$$

where $\alpha$ and $\beta$ (vide supra) lie within the limits specified in connection with equation 22 and $C_{r}$ is defined by equation 20.

That portion of the resistance encountered between the glomerulus and the locus of pressure equilibrium is given by the relation

$$
a R_{E}=\frac{P_{B}-\left(h^{\prime}+H\right)}{Q-q} \times 1328
$$

which divided by equation 3 yields

$$
a=\frac{P_{B}-\left(h^{\prime}+H\right)}{\left(P_{g}-P_{t}\right)}
$$

In terms of the characteristics of the renal vascular tree and the external forces applied to it, the fraction a is defined by the equation

$$
\text { (40) } a=\left\{1-\frac{R\left(h_{o}+\alpha \beta\right)}{2\left(P_{m}-P_{v}\right)\left[1328(1-\varphi)-\bar{\lambda} R_{E}^{\prime}\right]}\right\}
$$

where $\alpha$ and $\beta$ are the constants defined in equation 22, $\varphi$ is the hematocrit taken as a decimal. This relation holds within the limits imposed by the restrictive conditions specified above and can be drawn from the equations given in the text. .

The resistance, $R^{A}$, between the aorta and the locus of pressure equilibrium ${ }^{?}$ is

$$
\begin{aligned}
R^{A}=\frac{P_{m}-\left(h^{\prime}+H\right)}{Q} & \times 1328 \\
& =R_{A}+\frac{a R_{E} \times 1328}{\bar{\lambda} R_{E}+1328}=R_{A}+a R_{E}^{\prime}
\end{aligned}
$$

7 These two relations (equations 41 and 42 ) have been reported previously (42). However, the notations have been changed $\left(b=a R_{x}\right)$ and the permeability coefficient of the peritubular capillary network has been considered 
while the resistance, $R^{\mathbb{R}}$, from this equilibrium point to the vena cava at the level of the kidney is

$$
\text { (42) } \begin{aligned}
R^{E} & =\frac{\left(h^{\prime}+H\right)-P_{V}}{Q} \times 1328 \\
= & R_{V}+\frac{(1-a) R_{E} \times 1328}{\bar{\lambda} R_{E}+1328}=R_{V}+(1-a) R_{E}^{\prime}
\end{aligned}
$$

\section{Practical applications and limitations}

In one important respect the approach outlined above is different from that presented by Smith and associates (43), who assumed that filtration equilibrium is reached in the glomerulus. For such to be the case, most of the renal vascular resistance would have to be concentrated in the glomerular capillaries (which is equivalent to assigning practically zero resistance to the afferent, efferent and venular segments), and the gross permeability coefficient of the glomeruli would have to be as great as or greater than that of the peritubular capillaries. If such were the case, the filtration rate and the interstitial pressure would vary over wide ranges with variations in renal blood flow. The postulate that filtration equilibrium is reached in the glomerulus contradicts many theoretical and practical considerations (1) and is untenable. Lamport $(44,45)$ has used this assumption, and because the premise is untenable, the equations based thereon are also invalid. Other assumptions enter into his equations which are un-

as having a value many times greater than that of the glomerular capillaries. satisfactory, but space does not permit us to discuss them here.

In practical computations, $q, Q^{\prime}$ and $Q$ are corrected to standard surface area, $C_{m}$ is calculated by equation 16 and $h$ is calculated from equation 22 . Selecting the appropriate value of $H, P_{k}$ is calculated by equation $12 . P_{t}$ is calculated by equation 27 . These values are then introduced in equations 2,3 and $4 . R_{E}^{\prime}$ is then calculated from equation 32.

The above equations are subject to the following limitations:

a) Equations 1 to 4 by definition are applicable to clearance data where $E_{P A B}$ (or $E_{D}$ ) can be assumed to be high ( 90 per cent or above), so that the contribution of uncleared blood to renal resistance can be neglected, and where $E_{P A B}$ (or $E_{D}$ ) is known, the contribution of uncleared blood can be treated by equations 35 and 36 . But where $E_{P A B}$ (or $E_{D}$ ) has been reduced by disease the equations by definition are no longer applicable. The question of applicability in the presence of possible renal impairment must be considered on its own merits, with reference to every assumption made, as in the following discussion of renal resistances in patients with essential hypertension.

b) Equations 12 and 27 (and hence equations 2 and 3) should be applied with caution to patients with glomerular disease (acute and chronic glomerulonephritis, glomerulocapillary sclerosis, nephrosis, amyloidosis, etc.) because they involve the assumption that the gross glomerular permeability coefficient has the calculated and idealized normal value, $\bar{\lambda}$. For the same reason, the applicability of

TABLE I

Renal vascular resistances in normal subjects

$P_{m}$ indicates the mean arterial blood pressure, $60 \mathrm{q}, 60 \mathrm{Q}^{\prime}$, and $60 \mathrm{Q}$, the filtration rate, effective renal plasma flow and effective renal blood flow, respectively, per $1.73 \mathrm{sq}$. m. body surface area. Resistances are given in c.g.s. units (dynes sec. $\left.\mathrm{cm}^{-6}\right)$. The term a is defined in the text.

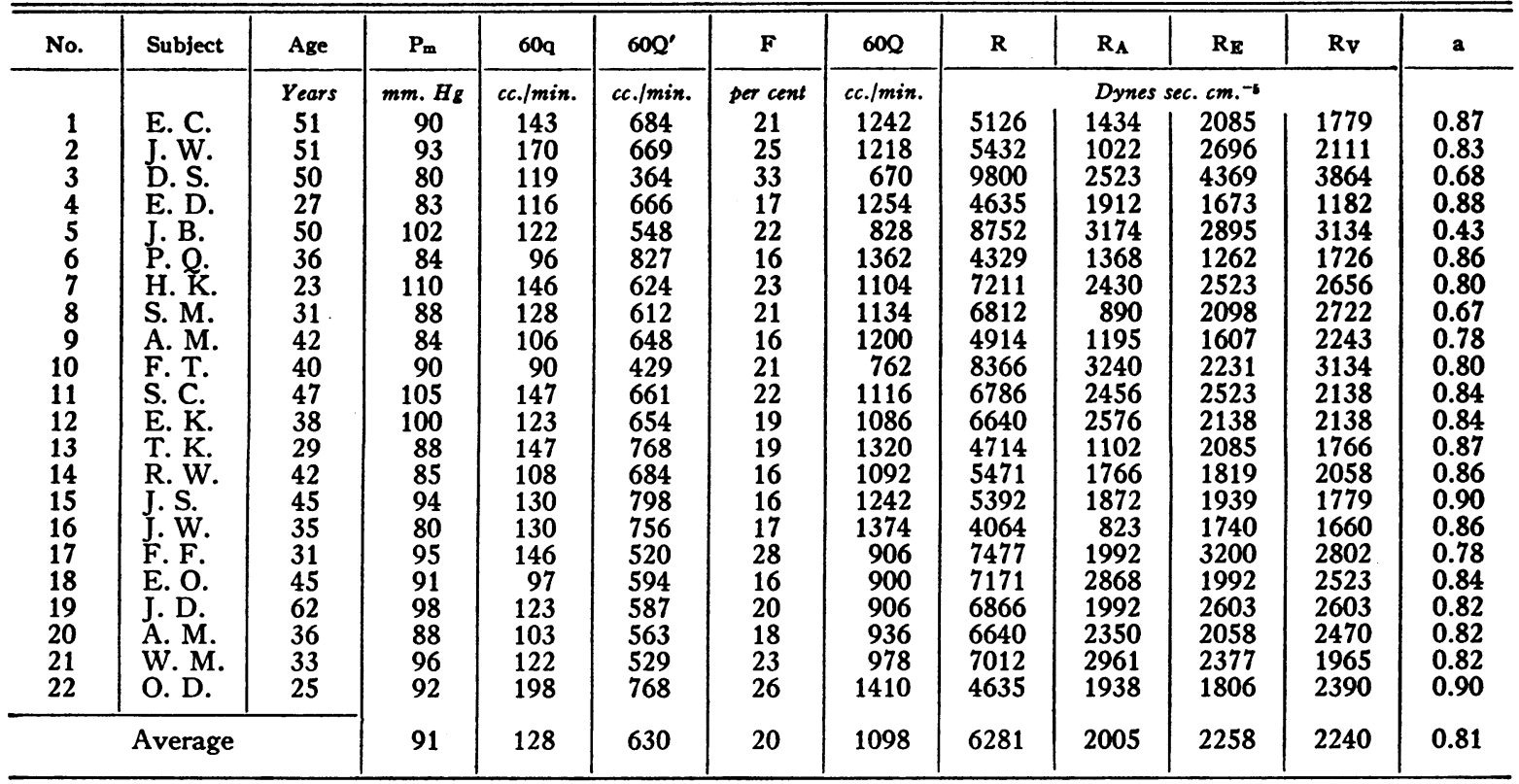


TABLE II

Renal resistances in subjects with essential hypertension

Data as in Table I

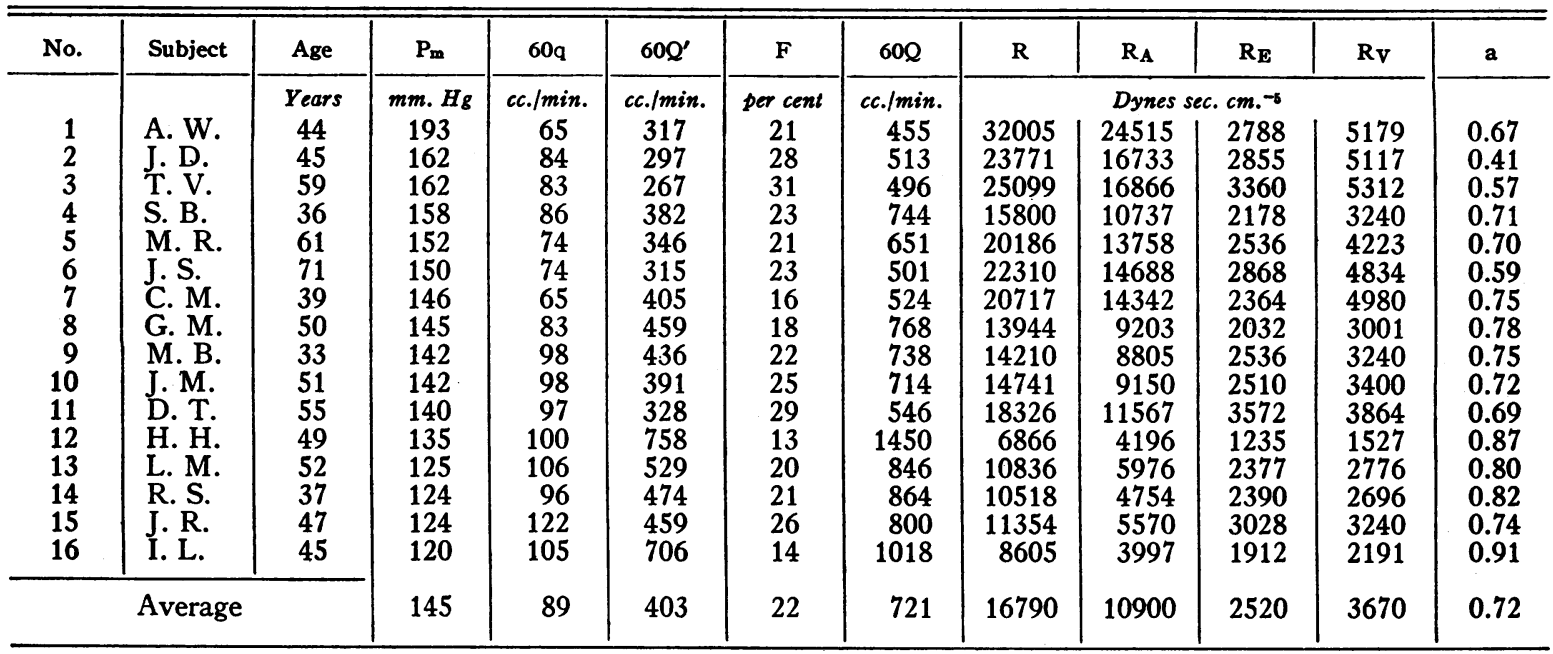

these equations to infants in whom the fetal glomerular membranes persist (32), and in senile individuals in whom many glomeruli may be canalized, is inappropriate.

c) For equation 22 to be valid, the systemic plasma concentration of total protein should not be below 5 nor above $8 \mathrm{gm} . / 100 \mathrm{cc}$. and the albumin/total protein ratio should be between 0.55 and 0.65 .

d) The renal blood flow, corrected for body surface area, should be above one-third $(400 \mathrm{cc}$./min.) of its normal value (1200 cc./min.); otherwise the concept of resistance as a simple ratio between flow and pressure (equations 1 to 4 inclusive) will probably become grossly inaccurate.

e) It is improbable that equation 12 will be valid if the filtration rate is markedly reduced ( $<50 \mathrm{cc} . / \mathrm{min}$.), and under these conditions it is less likely that the renal interstitial pressure, $\mathrm{H}$, can be equated with the intracapsular pressure.

f) The filtration fraction should not exceed 33 per cent of the renal plasma flow, because at higher values the approximation equation 27 becomes inaccurate.

g) Cases where the calculated values of $\mathrm{P}_{\mathrm{g}}$ are above 75 or below $45 \mathrm{~mm}$. $\mathrm{Hg}$ should be considered as of doubtful accuracy because great changes around the median value $60 \mathrm{~mm}$. $\mathrm{Hg}$ would imply excessive expansion or contraction of the glomerular membranes and consequently changes in the specific glomerular permeability coefficient.

h) Caution must be used in interpreting the causation of changes in $R_{A}, R_{E}$ or $R_{v}$. Active constriction of the efferent arterioles, for example, will by reduction of pressure distally elicit passive constriction in the venular system with an increase in $R_{V}$, while having converse passive effects upon the afferent arterioles and $R_{A}$. There is no way at the present time to distinguish passive from active changes in any of the vascular segments, and the effects of drugs, disease, etc. must be interpreted with this qualification.

\section{Renal resistances in normal subjects under standard conditions}

For the calculation of renal resistances in normal subjects under standard conditions we have used data reported by Bolomey and associates $^{8}$ and unpublished data collected in this laboratory by Drs. Maxwell, Breed and Fishman. The resistances given in Table I are calculated from the data there recorded using $P_{v}=10 \mathrm{~mm}$. $\mathrm{Hg}$ : where the plasma protein concentration was not available (about half of the cases), this value was assumed to be $7 \mathrm{gm} . / 100 \mathrm{cc}$. The calculated resistances recorded in Table I require only one comment: the resistance of the venular system, $R_{v}$, is significantly large in respect to the total renal resistance, $R$, and in the average equals the resistance of either the efferent or afferent arterioles.

The value a, representing the fraction of the

TABLE III

Renal resistances calculated from the data of Corcoran, Taylor and Page (47) on subjects with essential hypertension

\begin{tabular}{|c|c|c|c|c|c|c|c|}
\hline & $\mathbf{P}_{\mathrm{m}}$ & $60 q$ & $60 Q$ & $\mathbf{R}$ & $\mathbf{R}_{\mathbf{A}}$ & $\mathbf{R}_{\mathbf{E}}$ & $\mathbf{R V}$ \\
\hline $\begin{array}{l}\text { Highest } \\
\text { Lowest } \\
\text { Average }\end{array}$ & $\begin{array}{l}200 \\
108 \\
150\end{array}$ & $\begin{array}{r}152 \\
71 \\
99\end{array}$ & $\begin{array}{r}1459 \\
528 \\
848\end{array}$ & $\begin{array}{r}30215 \\
6786 \\
18675\end{array}$ & $\begin{array}{r}22284 \\
3944 \\
13930\end{array}$ & $\begin{array}{l}3744 \\
1622 \\
2549\end{array}$ & $\begin{array}{l}4878 \\
1368 \\
2536\end{array}$ \\
\hline
\end{tabular}

${ }^{8} \mathrm{We}$ are indebted to Dr. Lauson, and Drs. Corcoran, Taylor and Page for additional information not included in the published reports $(46,47)$. 
efferent resistance $R_{E}$ corresponding to the point at which pressure equilibrium is reached, needs no comment at this time, the data supplying a basis of reference in connection with shifts in this value during disturbances in the renal circulation.

\section{Renal resistances in subjects with essential hypertension}

The data on hypertensive subjects analyzed here comprise 11 subjects reported by Bolomey and co-workers (46) (Table II), five subjects on whom unreported data were available in this laboratory, and 35 subjects reported by Corcoran, Taylor and Page $(47,48)$ (Table III). Here again $P_{v}$ was assumed to be $10 \mathrm{~mm}$. $\mathrm{Hg}$ and the plasma protein concentration where not available was taken as $7 \mathrm{gm} . / 100 \mathrm{cc}$.

It is known that in advanced stages of essential hypertension the extraction ratio of diodrast or PAH may be reduced (49-51) to such an extent that the clearance of these substances falls markedly below the total renal plasma flow. It is also known that the apparent filtration fraction may increase in some subjects to values ranging from 0.30 to 0.50 , a circumstance which Goldring and associates (52) attributed to the formation of impotent nephrons in which, despite the persistance of glomerular filtration, tubular extraction is impaired. Whether the two phenomena are related has not been deter-

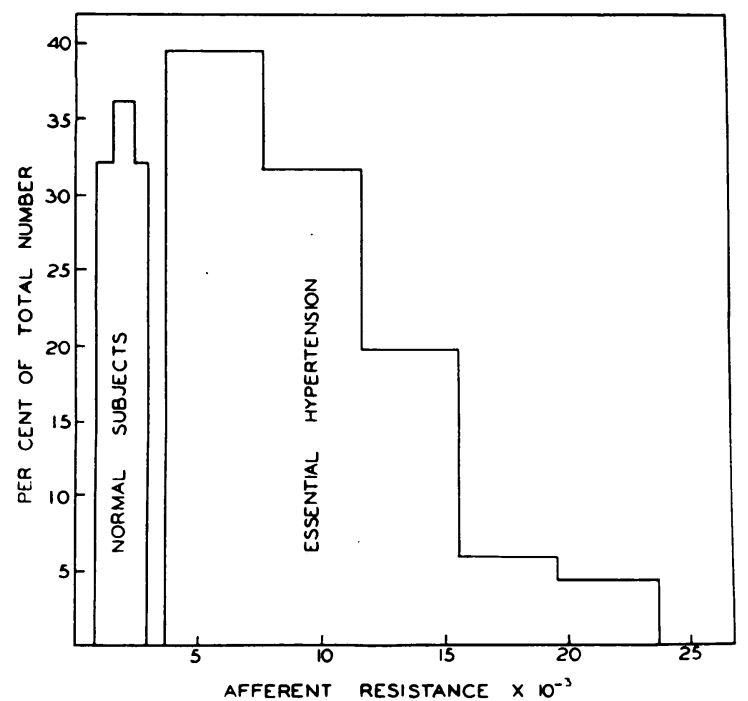

Fig. 1. Distribution of AfFerent Arteriolar Resistance in Normal and Hypertensive Subjects
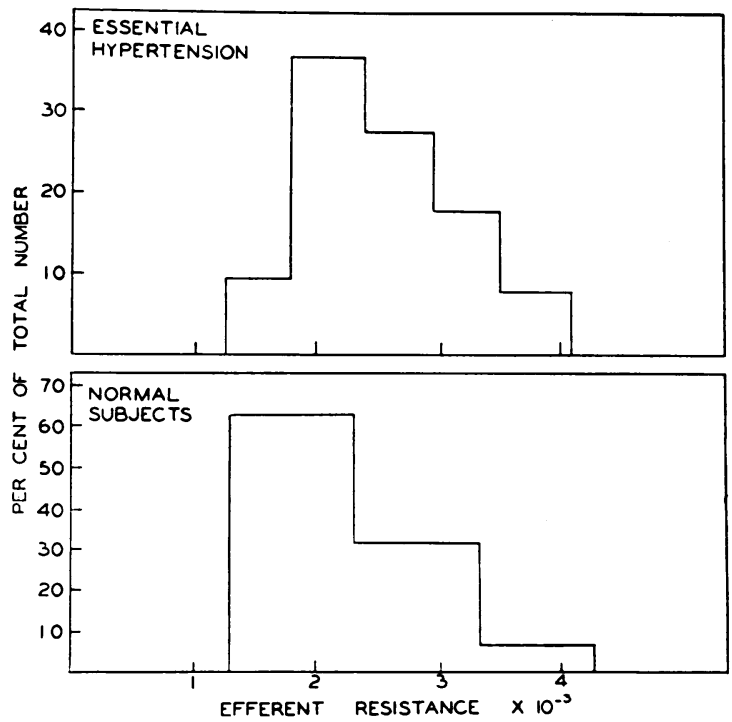

Fig. 2. Distribution of EfFerent Arteriolar Resistance in Normal and Hypertensive Subjects

mined, but it is highly probable that in any subject in which renal impairment has progressed to the point where the apparent filtration fraction is above the normal parameter (32) of $\mathrm{m}+2 \sigma$, (c. 0.27), assumption 111 is inapplicable. Consequently we have selected for analysis only those subjects in whom the filtration fraction lies below 0.30. We have furthermore excluded subjects in whom the filtration rate is less than $65 \mathrm{cc} / \mathrm{min}$., or the renal blood flow below 400 $\mathrm{cc} . / \mathrm{min}$. None of the subjects showed evidence of cardiac failure or specific renal disease.

The results of our analysis of the two series are so similar that they will be considered together in the following discussion and in the figures.

The following points merit specific comment:

a) The frequency distribution of $R_{A}$ among the hypertensive subjects is compared with the normal distribution in Figure 1. The lowest value of $R_{A}$ among the hypertensive subjects exceeds the highest normal value.

b) Although $R_{E}$ (and consequently $\left.R_{E}^{\prime}\right)^{9}$ tends to be moderately increased, the mode lies below the upper normal limit in the frequency distribution curve (Figure 2). The data will not enable us to determine whether this increase

\footnotetext{
${ }^{9} R_{F}$ rather than $R_{E}^{\prime}$ has been given in Tables I, II and III because the latter can be calculated directly as $\mathrm{R}-$ $\left(R_{A}+R_{V}\right)$.
} 

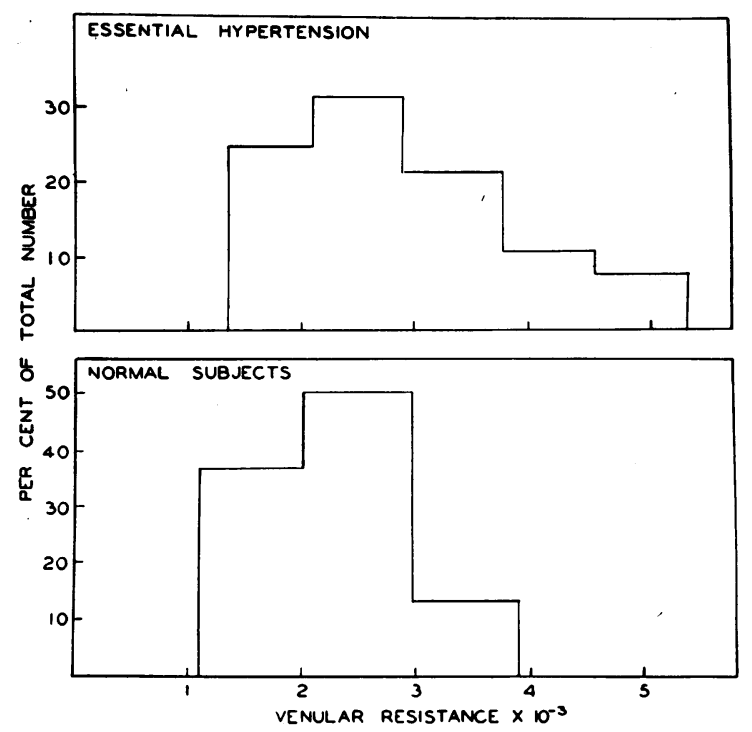

Fig. 3. Distribution of Venular Resistance in Normal and Hypertensive Subjects

is active or whether it is a passive consequence of the reduction in glomerular pressure.

c) Venular resistance is also elevated in the mean, but the mode still lies within the upper normal range (Figure 3 ).

d) Total resistance, $R$, is increased in nearly all hypertensive subjects, this increase being attributable predominantly to the increase in $R_{A}$ (Figure 4).

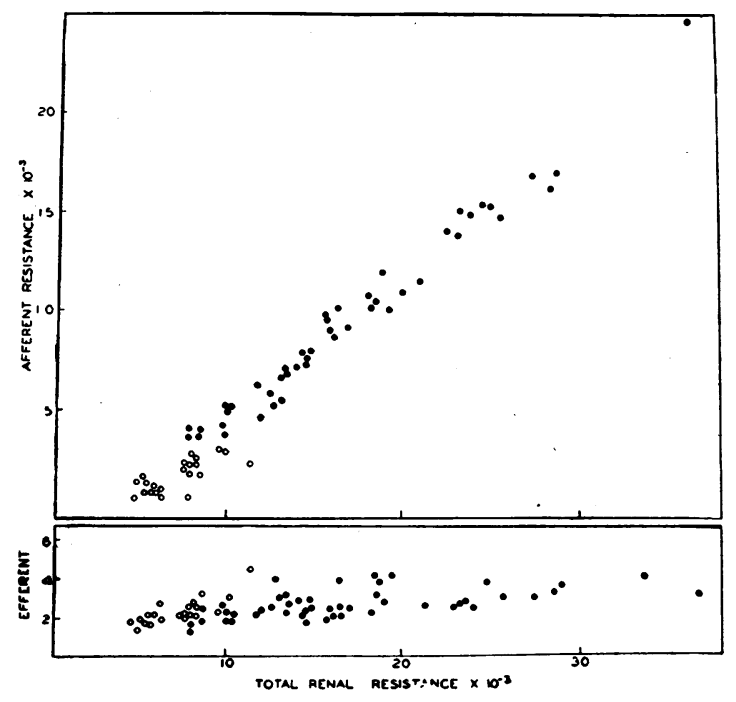

Fig. 4. Variations of AfFerent (Above) AND Efferent (Below) Arteriolar Resistance with the Total Renal Resistance in Normal (Open Circles) and Hypertensive (Dots) Subjects e) One might anticipate that the increased afferent resistance would parallel the increase in systemic arteriolar resistance, in which case the renal blood flow and filtration rate would remain unchanged from normal in the face of increased arterial pressure. However, such is not the case; the renal resistance increases relatively more than the systemic resistance. To illustrate this point we note that in the majority of hypertensive subjects reported by Bolomey and associ-

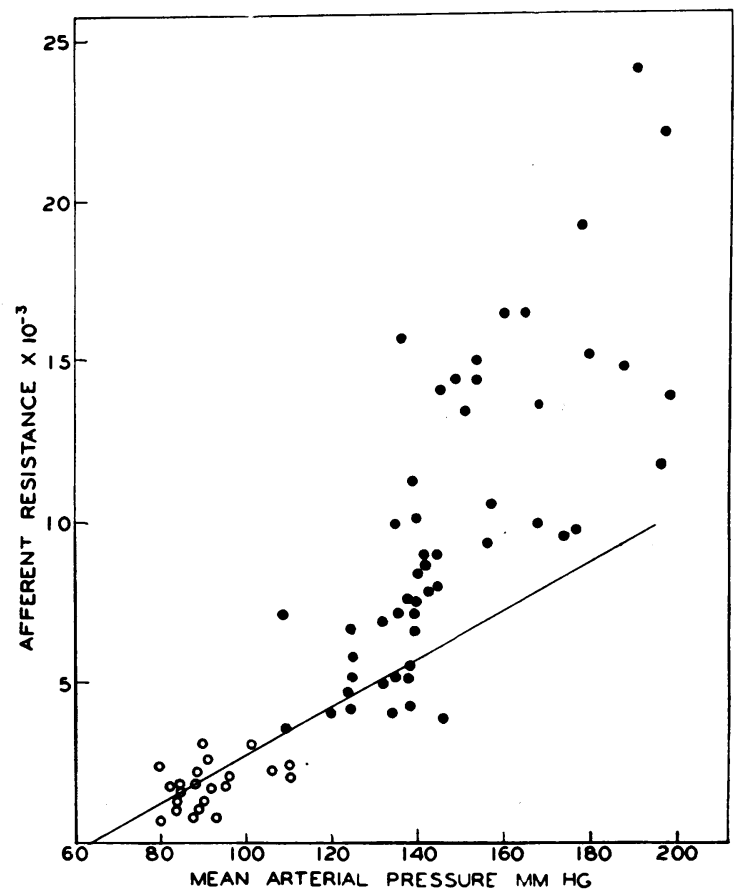

Fig. 5. Afferent Arteriolar Resistance in Relation to Mean Arterial Pressure in Normal (Open Circles) and Hypertensive (Dots) Subjects

The line indicates the changes in afferent resistance to be expected with increasing arterial pressure if renal blood flow and filtration rate retained the average values observed in the normal subjects represented by the open circles.

ates (our Table II), the cardiac output had the same modality and range as in their control subjects (our Table I). Therefore, the mean arterial pressure may be used as a rough index of the resistance in the systemic arteriolar bed. If in equation 2 we substitute the average normal values of $Q(18.3 \mathrm{cc} . / \mathrm{sec}$.) as given in Table I and the average value of $P_{g}$ as calculated from these data ( $=63.5 \mathrm{~mm}$. $\mathrm{Hg}$ ), and solve for $R_{A}$ as a function of $P_{m}$, we obtain the solid line in Figure 5. This line represents the values of $R_{A}$ re- 
quired at increasing values of $\mathrm{P}_{\mathrm{m}}$ to yield a constant renal blood flow and filtration rate in the face of increasing $P_{m}$. It is clear that with increasing hypertension, there is a relatively greater increase in resistance in the afferent renal arterioles than in the systemic arterioles as a whole. These calculations give more exact expression to the well demonstrated fact that the renal blood flow tends to decrease below the normal value with advancing disease, despite the increase in blood pressure (31).

Our analysis indicates that the consistent and characteristic change in the renal circulation in essential hypertension is in afferent arteriolar resistance, which may be increased several fold: the increase in the efferent arteriolar and venular resistance, slight as it actually is, may be in part attributable to the passive decrease in caliber which results from the resulting decrease in glomerular and post-glomerular pressure. ${ }^{10}$

When Goldring and colleagues (52) concluded that essential hypertension was characterized by increased efferent arteriolar tone $\left(R_{E}\right.$ as here defined), they attempted no quantitative analysis of afferent arteriolar or venular tone, and they were led to their conclusion by inadequate analysis of hemodynamic factors, as cited earlier in this paper. Our present study forces us to accept that the increase in $R_{E}$ as here calculated is at most a slight one; the outstanding change in renal hemodynamics is reflected in the increase in afferent resistance. Our analysis throws no light on whether this increase is anatomical or functional, but the demonstration by Goldring and associates (52) that the renal hyperemia induced in most hypertensive subjects by pyrogen is comparable in degree to that induced in normal subjects is evidence that the predominant factor is functional.

\section{SUMMARY}

1. Equations are developed for the calculation of the total renal resistance, $R$, the afferent arteriolar resistance, $R_{A}$, the pure efferent, $R_{E}$, and the net efferent arteriolar resistance $R_{E}^{\prime}(a$ term that includes the diversion of the glomeru-

\footnotetext{
${ }^{10}$ In view of the above results, the excessive increase in filtration fraction which is so generally characteristic of the disease in its advanced stages should be referred in considerable part to failure of tubular clearance (impotent nephrons) rather than to increased glomerular pressure.
}

lar filtrate around the efferent arteriole), and the venular resistance, $R_{v}$.

2. The calculations are based upon the clinically determinable variables of mean arterial blood pressure, the renal blood flow and plasma flow, the filtration rate, the protein concentration of the blood and the renal venous (or the femoral) pressure. Assumptions with respect to renal interstitial pressure and other matters pertinent to the validity of the working equations are stated in the text. Some of the limiting clinical conditions under which the working equations are applicable are defined.

3. Calculations are presented for the above resistances in 22 normal subjects who had been examined under standard conditions. A hitherto unrecorded datum is the relatively large magnitude of the renal venular resistance, which in the average equals the resistance of either the efferent or afferent arterioles.

4. Data on 51 subjects with essential hypertension reveal that the predominant change in the renal circulation in this disease is an increase in afferent arteriolar resistance. This increase is relatively greater than the increase in the resistance of the systemic arterioles.

\section{REFERENCES}

1. Gómez, D. M., Hemodynamics of the renal circulation. La Rev. Scientif., 1947, No. 3272, fasc. 8, 451.

2. Gómez, D. M., Hémodynamique et Angiocinétique. Hermann et Cie, Paris, 1941.

3. Leconte de Noüy, P., Viscosité et phénomènes optiques. Actualités Scientif., 1936, 401, 1.

4. Whittaker, S. R. F., and Winton, F. R., The apparent viscosity. of blood flowing in the isolated hindlimb of the dog, and its variation with corpuscular concentration. J. Physiol., 1933, 78, 339.

5. Fåhraeus, R., and Lindqvist, T., The viscosity of the blood in narrow capillary tubes. Am. J. Physiol., 1931, 96, 562.

6. Vimtrup, B., On the number, shape, structure and surface area of the glomeruli in the kidneys of man and mammals. Am. J. Anat., 1928, 41, 123.

7. Goldring, W., Chasis, H., Ranges, H. A., and Smith, H. W., Relations of effective renal blood flow and glomerular filtration to tubular excretory mass in normal man. J. Clin. Invest., 1940, 19, 739.

8. Landis, E. M., Capillary pressure and capillary permeability. Physiol. Rev., 1934, 14, 404.

9. Green, H. D., Lewis, R. N., Nickerson, N. D., and Heller, A. L., Blood flow, peripheral resistance and vascular tonus, with observations on the relationship between blood flow and cutaneous temperature. Am. J. Physiol., 1944, 141, 518. 
10. Batten, W., Ogle, B. C., Rapela, C., Hege, J. R., Jr., Little, J. M., and Green, H. D., Relationship between arterial pressure and renal blood flow. Federation Proc., 1948, 7, 6.

11. Selkurt, E. E., The relation of renal blood flow to effective arterial pressure in the intact kidney of the dog. Am. J. Physiol., 1946, 147, 537.

12. Pappenheimer, J. R., and Maes, J. P., A quantitative measure of the vasomotor tone in the hindlimb muscles of the dog. Am. J. Physiol., 1942, 137, 187.

13. Gómez, D. M., Les lois physiques de l'hémodynamique. Leur détermination piézographique. Actualités Scientif., 1937, 511, 1.

14. Gómez, D. M., Décroissance en fonction du temps de la pression artérielle, sa détermination chez l'homme par un dispositif piézoélectrique. Compt. rend. Acad. d. sc., 1936, 202, 1814.

15. Gómez, D. M., Caractéristiques physiques des vaisseaux, débit circulatoire et loi de décroissance, en fonction du temps, de la pression artérielle. Compt. rend. Acad. d. sc., 1936, 203, 1030.

16. Gómez, D. M., Syndromes artério-capillaires et paramètres piézographiques. Presse méd., 1937, 45, 354 .

17. Gómez, D. M., and Weil, C., Sur la limite statique de la pression artérielle. Compt. rend. Soc. de biol., 1936, 123, 957.

18. Apéria, A., Hemodynamical studies. Skandinav. Arch. f. Physiol., 1940, Suppl. 16, 83, 1.

19. Burton, A. C., Nichol, J. T., Girling, F., and Jerrard, W., A new view of relation between pressure and flow in a vascular bed, and validity of 'peripheral resistance.' Federation Proc., 1950, 9, 20.

20. Gómez, D. M., Further studies on renal hemodynamics. In preparation.

21. Böger, A., and Wezler, K., Die Bestimmung des arteriellen Gesamtwiderstandes am Menschen. Arch. f. exper. Path. u. Pharmakol., 1937, 186, 43.

22. Vaquez, H., Gley, P., and Gómez, I). M., Une nouvelle étape de la sphygmomanométrie. Presse méd., $1931,16,281$.

23. Vaquez, H., Gley, P., and Gómez, I). M., Etude théorique et pratique de la mesure de la pression moyenne par la méthode oscillométrique. Presse méd., 1931, 39, 1309.

24. Vaquez, H., and Gómez, D. M., Pression moyenne et hypertension artérielle. Bull. Acad de Méd., 1931, No. 7, 105, 234.

25. Vaquez, H., Gley, P., and Gómez, D. M., Un nouvel indicateur de pression: le Kymomètre. La Presse méd., 1931, 39, 1802.

26. Gley, P., and Gómez, I). M., La détermination de la pression moyenne par la méthode oscillométrique. J. de physiol. et de path. gén., 1931, 29, 38.

27. Gley, P., and Gómez, D. M., Le déterminisme des oscillations supramaximales et inframinimales. J. de physiol. et path. gén., 1931, 29, 695.

28. Gley, P., and Gómez, D. M., La détermination des pressions moyenne et minima par la méthode oscillométrique. Presse méd., 1931, 39, 284.
29. Maxwell, M. H., Breed, E. S., and Schwartz, I. L., Renal venous pressure in chronic congestive heart failure. J. Clin, Invest., 1950, 29, 342.

30. Bradley, S. E., and Bradley, G. P., The effect of increased intra-abdominal pressure on renal function in man. J. Clin. Invest., 1947, 26, 1010.

31. Winton, F. R., Physical factors involved in the activities of the mammalian kidney. Physiol. Rev., $1937,17,408$.

32. Smith, H. W., The Kidney: Structure and Function in Heảlth and Disease. Oxford University Press, New York, 1951.

33. Gottschalk, C. W., An experimental and comparative study of renal and interstitial pressure. Am. J. Physiol., 1950, 163, 716.

34. Crowder, C. H., Jr., Deane, N., Morales, P., and Gómez, D. M., Measurement of intrarenal pressure. In preparation.

35. Wells, H. S., Youmans, J. B., and Miller, D. G., Jr., A formula and nomogram for the estimation of the osmotic pressure of colloids from the albumin and total protein concentrations of human blood sera. J. Clin. Invest., 1933, 12, 1103.

36. Scatchard, G., Batchelder, A. C., and Brown, A., Preparation and properties of serum and plasma proteins. VI. Osmotic equilibria in solutions of serum albumin and sodium chloride. J. Am. Chem. Soc., 1946, 68, 2320.

37. Scatchard, G., Batchelder, A. C., and Brown, A., Chemical, clinical and immunological studies on the products of human plasma fractionation. VI. The osmotic pressure of plasma and of serum albumin. J. Clin. Invest., 1944, 23, 458.

38. Wies, C. H., and Peters, J. P., The osmotic pressure of proteins in whole serum. J. Clin. Invest., 19.37, 16, 93.

39. Verney, E. B., Personal communication of provisional and unpublished data of G. S. Adair.

40. Krogh, A., Anatomy and Physiology of Capillaries. Revised Edition. Yale Iniversity Press, New Haven, 1929.

41. Book, M. H., The secreting area of the glomerulus. J. Anat., 1936, 71, 91.

42. Gómez, D. M., Calculation of effective afferent and efferent renal resistance. Federation Proc., 1948, 7, 41 .

43. Smith, H. W., Chasis, H., Goldring, W., and Ranges, H. A., Glomerular dynamics in the normal human kidney. J. Clin. Invest., 1940, 19, 751.

44. Lamport, H., Formulae for afferent and efferent arteriolar resistance in the human kidney: an application to the effects of spinal anesthesia. J. Clin. Invest., 1941, 20, 535.

45. Lamport, H., The relative changes in afferent and efferent arteriolar resistance in the normal human kidney. J. Clin. Invest., 1941, 20, 545.

46. Bolomey, A. A., Michie, A. J., Michie, C., Breed, E. S., Schreiner, G. E., and Lauson, H. D., Simultaneous measurement of effective renal blood flow and 
cardiac output in resting normal subjects and patients with essential hypertension. J. Clin. Invest., 1949, 28, 10.

47. Corcoran, A. C., Taylor, R. D., and Page, I. H., Circulatory responses to spinal and caudal anesthesia in hypertension: relation to the effect of sympathectomy. II. Effect on renal function. Am. Heart J., 1948, 36, 226.

48. Corcoran, A. C., and Page, I. H., Personal communication.

49. Bradley, S. E., Curry, J. J., and Bradley, G. P., Renal extraction of $\mathrm{p}$-aminohippurate in normal subjects and in essential hypertension and chronic diffuse glomerulonephritis. Federation Proc., 1947, 6, 79.

50. Reubi, F. C., and Schroeder, H. A., Can vascular shunting be induced in the kidney by vasoactive drugs? J. Clin. Invest., 1949, 28, 114.

51. Cargill, W. H., The measurement of glomerular and tubular plasma flow in the normal and diseased human kidney. J. Clin. Invest., 1949, 28, 533.

52. Goldring, W., Chasis, H., Ranges, H. A., and Smith, H. W., Effective renal blood flow in subjects with essential hypertension. J. Clin. Invest., 1941, 20, 637. 